\title{
Indications and rates of lower segment caesarean section at tertiary care hospital - an analytical study
}

\author{
Ashmita Jawa*, Swati Garg, Arihant Tater, Urvashi Sharma
}

Department of Obstetrics and Gynaecology, Mahatma Gandhi Medical College and Hospital, Jaipur, Rajasthan, India

Received: 19 July 2016

Accepted: 28 August 2016

\section{*Correspondence:}

Dr. Ashmita Jawa,

E-mail: ashijawa@gmail.com

Copyright: (c) the author(s), publisher and licensee Medip Academy. This is an open-access article distributed under the terms of the Creative Commons Attribution Non-Commercial License, which permits unrestricted non-commercial use, distribution, and reproduction in any medium, provided the original work is properly cited.

\begin{abstract}
Background: Over the past few decades, there has been a rise in the rates of caesarean section globally. The reasons for this are multifactorial including changes in women's preferences, a growing number who have previously had a caesarean delivery and technological advances which aid in early identification of a compromised fetus.

Methods: This study aims to analyze the rates and indications of lower segment caesarean section (LSCS) in our institution. This retrospective study was conducted over a period of six months - December 2015 to May 2016 at Mahatma Gandhi Medical College and Hospital, Jaipur. Total number of patients who delivered in our hospital during the defined study period was recorded and a statistical analysis of various parameters was done.

Results: The total number of women delivered over the study period was 1645, out of which caesarean sections (CS) were 523. The overall CS rate calculated was 31.8\%. Previous LSCS was the leading indication to the CS rate.

Conclusions: Individualization of the indication and obstetric audits can help in reducing both maternal and peri-natal morbidity and mortality.
\end{abstract}

Keywords: Caesarean section, Previous LSCS, Indication of CS

\section{INTRODUCTION}

Since 1985, the international healthcare community has considered the ideal rate for caesarean sections to be between $10 \%$ and $15 \%$. Since then, a rising trend of caesarean sections has been noted with the advent of electronic fetal monitoring, better operative techniques and availability of tertiary care neonatal facilities. ${ }^{1}$ When medically justified, a caesarean section (CS) can effectively prevent maternal and perinatal mortality and morbidity. ${ }^{1}$ As with any surgery, caesarean sections are associated with short term and long term risks which can extend many years beyond the current delivery and affect the health of the woman, her child, and future pregnancies. CS may be associated with an increased risk of CS related morbidity, abdominal pain , hysterectomy, ureteral tract and vesicle injury, neonatal respiratory morbidity, fetal death, placenta accreta/percreta, and uterine rupture in future pregnancies. ${ }^{2}$ These risks are higher in women with limited access to comprehensive obstetric care. In recent years, governments and clinicians have expressed concern about the rise in the numbers of caesarean section births and the potential negative consequences on maternal and infant health. High caesarean rates are an issue of international public health concern. ${ }^{3,4}$

The objective of this study was to analyse the rates and trends of LSCS in our institution in modern day obstetrics.

\section{METHODS}

The present study was carried out retrospectively over a period of six months- from December 2015 to May 2016 in the department of obstetrics and gynaecology, Mahatma Gandhi Medical College and Hospital, Jaipur; a tertiary care institute which cares for over 3000 
institutional deliveries per year. All cases of institutional deliveries during the defined study period were recorded and a statistical analysis of various parameters- age, parity, and period of gestation and indication for caesarean section was done after gaining approval from the institutional ethics committee.

\section{RESULTS}

The total numbers of women delivered over the study period were 1645, out of which CS deliveries were 523. Overall, caesarean rate calculated for our institution was $31.8 \%$.

\section{Table 1: Distribution of patients who underwent} LSCS by Age.

\begin{tabular}{|lll|}
\hline Age group & No. of cases & $\%$ \\
\hline$<20$ years & 54 & 10.3 \\
\hline 21-25 years & 270 & 51.6 \\
\hline 26-30 years & 153 & 29.3 \\
\hline 31-35 years & 41 & 7.8 \\
\hline 36-40 years & 5 & 1 \\
\hline Total & $\mathbf{5 2 3}$ & $\mathbf{1 0 0 \%}$ \\
\hline
\end{tabular}

Maximum no. of caesarean sections - 270 of 523 (51.6\%) were in the age group of 21-25 years followed by $29.3 \%$ patients in the age group of 26-30 years. Only $1 \%$ of the cases belonged to the elderly age group of 36-40 years (Table 1).

Table 2: Comparison of indications of LSCS according to parity.

\begin{tabular}{|lll|}
\hline Parity & No. of cases & Percentage $(\%)$ \\
\hline Multipara & 297 & 56.79 \\
\hline Primi & 226 & 43.21 \\
\hline Total & $\mathbf{5 2 3}$ & $\mathbf{1 0 0}$ \\
\hline
\end{tabular}

Maximum no. of caesarean sections were multiparous females - 57\% (297/523 cases), close to the primigravida group contribution of $43 \%$ (Table 2), the contributory factor to the majority group being the previous LSCS as the leading indication to the CS rate.

Table 3: Percentage of LSCS in relation to Period of gestation.

\begin{tabular}{|lll|}
\hline Period of gestation & No. of cases & Percentage $(\%)$ \\
\hline Preterm $(<37$ weeks) & 118 & 22.56 \\
\hline Term $(\geq 37$ weeks $)$ & 405 & 77.44 \\
\hline Total & $\mathbf{5 2 3}$ & $\mathbf{1 0 0}$ \\
\hline
\end{tabular}

$77 \%$ (405 of 523) of the study group were term patients; term being defined as 37 weeks period of gestation or more (Table 3).

Previous LSCS was the most common indication of caesarean section in the present study accounting for 125 of all CS cases (23.9\%). Fetal distress accounted for $16 \%$; Non progress of labor/failed induction - 13\%; Hypertensive disorders of pregnancy (HDP) - 11.6\%; Breech - 6.7\%; cephalopelvic disproportion (CPD) and Oligohydramnios/IUGR account for $5.9 \%$ each of total caesarean sections respectively. Rest in decreasing order were medical disorders of pregnancy (excluding HDP), antepartum haemorrhage (APH), malpresentation, obstructed labor, bad obstetric history $(\mathrm{BOH})$ and cord prolapse respectively (Table 4).

Table 4: Indications of LSCS.

\begin{tabular}{|lll|}
\hline Indications & No. of cases & $\%$ \\
\hline Previous LSCS & 125 & 23.90 \\
\hline Fetal distress & 84 & 16.06 \\
\hline $\begin{array}{l}\text { NPOL (including failed } \\
\text { induction) }\end{array}$ & 68 & 13.00 \\
\hline Breech & 35 & 6.69 \\
\hline CPD & 31 & 5.93 \\
\hline $\begin{array}{l}\text { Hypertensive disorders of } \\
\text { pregnancy }\end{array}$ & 61 & 11.66 \\
\hline Antepartum haemorrhage & 17 & 3.25 \\
\hline Obstructed labor & 11 & 2.10 \\
\hline Malpresentation & 14 & 2.68 \\
\hline Multifetal gestation & 11 & 2.10 \\
\hline Oligohydramnios/IUGR & 31 & 5.93 \\
\hline Cord prolapse & 5 & 0.96 \\
\hline Bad obstetric history & 8 & 1.53 \\
\hline $\begin{array}{l}\text { Medical disorders of } \\
\text { pregnancy (excluding HDP) }\end{array}$ & 22 & 4.21 \\
\hline Total & $\mathbf{5 2 3}$ & $\mathbf{1 0 0}$ \\
\hline
\end{tabular}

Caesarean due to fetal distress, hypertensive disorders, APH, oligohydramnios/IUGR had almost equal occurrence amongst primigravida versus multiparous females. However, CS due to NPOL, Breech, CPD, Obstructed labor was more in the primi group (Figure 1).

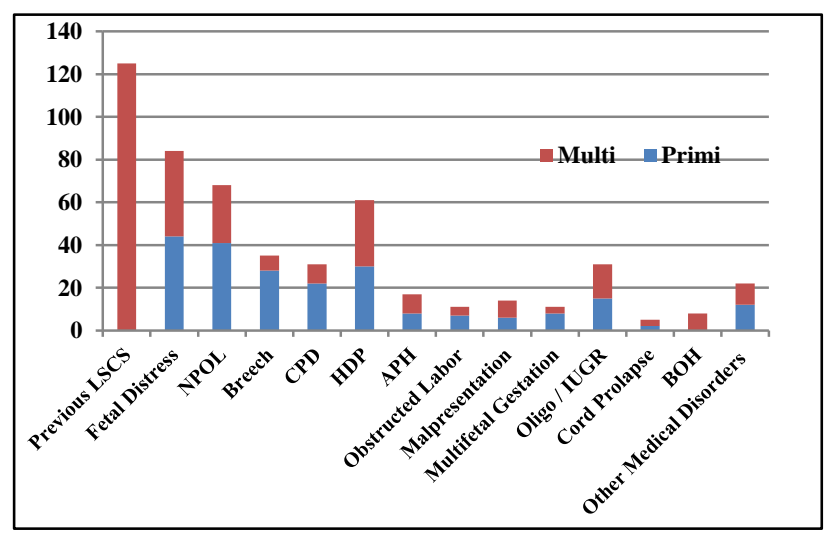

Figure 1: Comparison of indications of LSCS in primiparas and multipara.

The figure illustrates the case distribution in terms of no. of LSCS (plotted on y-axis) against indications of LSCS (plotted on $\mathrm{x}$-axis) according to parity. 


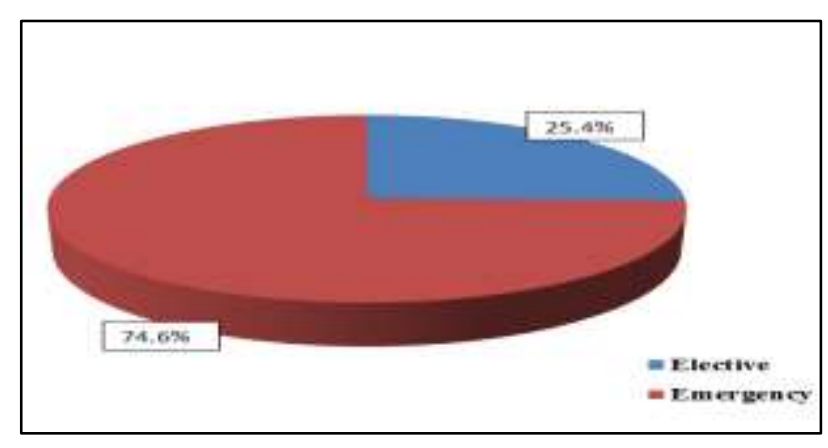

Figure 2: Comparison of elective and emergency LSCS.

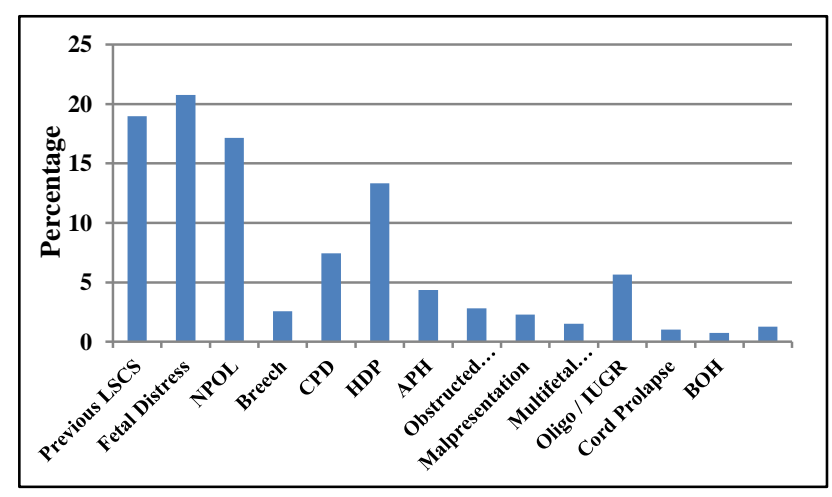

Figure 3: Indications of LSCS in emergency cases.

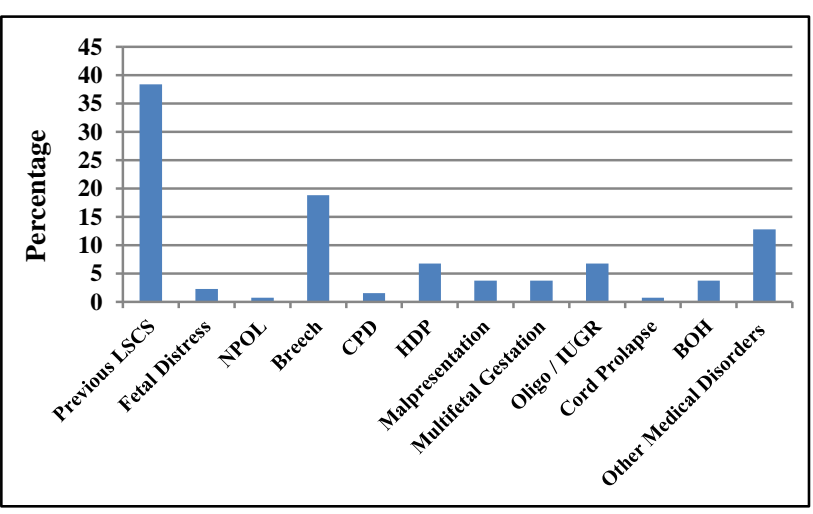

Figure 4: Indications of LSCS in elective cases.

A total of 390 of 523 cases $(74.6 \%)$ were performed due to emergency indications whereas $133(25.4 \%)$ cases were elective (Figure 2). A comparison of indications in emergency and elective cases has been described (Figure 3, 4). Fetal distress, previous LSCS, NPOL (including failed induction) and HDP were the leading indications in the emergency indications' group in the order stated (Figure 3); whereas previous caesarean was the leading indication amongst the elective group followed by breech and medical disorders of pregnancy (Figure 4).

\section{DISCUSSION}

In our study, caesarean rate was $31.8 \%$. This is almost double the accepted upper norm of World Health
Organization of $15 \% .^{1}$ Authentic studies on caesarean section rate in India could not be found. A study on the rates of caesarean section in the medical college and hospital GMERS, Sola, Ahmedabad stated a rate of $25.1 \% .^{5}$ However, it may be difficult to contain the rates in tertiary care institutes, catering to a large population of referred cases.

The WHO expert panel in its worldwide ecologic study to assess the association between caesarean sections, maternal and neonatal mortality made the following observations: ${ }^{1}$

- Increases in CS rates up to $10-15 \%$ at population level are associated with decrease in maternal, neonatal and infant mortality. Above this level, the rate of caesarean section is no longer associated with reduced mortality

- Below a caesarean section rate of $10 \%$, maternal and neonatal mortality decreased when caesarean rates increased. No effect on mortality rates was observed at CS rate between 10-30\%

- Current data is insufficient to assess the link between maternal and newborn mortality and rates of caesarean section above $30 \%$.

There has been a steady increase in the rates of CS in both developed and developing countries although there exists a wide variation in caesarean rates between the two owing to limited resources in the developing nations. The caesarean section rate in Africa was $6.2 \%$ of which most common indication was obstructed labor (31\%), in contrast to previous LSCS in our study. ${ }^{6}$ In United Kingdom, the caesarean rate was $24.1 \%$ of all live births. ${ }^{7}$

Analysis of age of the patients showed that $80 \%$ of cases were in the age group of maximum fertility i.e. between 20-30 years. A study in IPGMR showed $89 \%$ amongst this age group. ${ }^{5,8}$ A study of Latin American hospital showed maximum incidence $>30$ years in primi patients, which might reflect delayed age of marriages in the western countries. ${ }^{5,9}$

The increased rates of caesarean section are thought to be due mainly to changed risk profiles both for expectant mothers and for their yet unborn children, as well as an increase in caesarean section by maternal request. Although a previous caesarean section does not necessarily mean a repeat caesarean delivery in subsequent pregnancies, the sense of security of physicians and mothers seems to be responsible for repeated caesarean deliveries. $^{10}$

Another much-discussed reason for the observed increase in caesarean deliveries is the rise in assisted reproductive interventions. Reproductive interventions in themselves lead to an increased caesarean rate, but maternal anxiety about a healthy outcome for her child may also play an important part. ${ }^{11}$ 
In our study, trial for vaginal birth after caesarean (VBAC) was given judiciously in patients where applicable according to ACOG guidelines for trial of VBAC - with previous 1CS (transverse scar), singleton pregnancy with vertex presentation in spontaneous labor. ${ }^{12}$ No trial was given to patients with previous two or more scars due to presumed risk of maternal and fetal complications.

One limitation of observational studies is that the associations with poor outcomes could be due to the conditions that trigger the caesarean rather than the caesarean section itself. $^{2}$ It is also possible that caesarean section rates were overestimated since vaginal deliveries at home may have been underreported.

No standard classification system exists for indications of CS. ${ }^{13,14}$ A major challenge is that definitions are not standardized and indications can be multiple or related. For example, there may be a difference in opinion of the authors in classifying the patients under a particular category. Despite challenges in classification, identifying the most common indications for caesarean section is important to target prevention strategies. ${ }^{12}$

\section{CONCLUSION}

There has been a steady increase in the rates of CS in both developed and developing countries. Individualization of the indication and careful evaluation can help us limit early peri-natal morbidity and mortality. Previous CS was the leading indication for caesarean deliveries in the study group. It is important that efforts to reduce the overall caesarean rate focus on reducing the primary CS rate and judicious use of VBAC be given in cases of previous caesarean to decrease rate of repeat CS. Obstetric audits in the institution, following standardized guidelines and practice of evidenced-based obstetrics shall help in reducing the peri-natal morbidity and mortality.

\section{ACKNOWLEDGEMENTS}

Authors would like to acknowledge the Medical Records Department of our institution for allowing me to access the in-patient record files. Authors would also like to thank Ashish, the department office assistant who assisted me in the maintaining the records.

\section{Funding: No funding sources}

Conflict of interest: None declared

Ethical approval: The study was approved by the Institutional Ethics Committee

\section{REFERENCES}

1. WHO Statement on caesarean section rates; 2015, WHO reference number: WHO/RHR/15.02. Available http://www.who.int/reproductivehealth/publications/ maternal_perinatal_health/cs-statement/en/.

Accessed on 15 July 2016.

2. Belizán JM, Cafferata ML, Althabe F, Buekens P. Risk of patient choice caesarean. Birth. 2006;33:1679.

3. Marshall NE, Fu R, Guise JM. Impact of multiple caesarean deliveries on maternal morbidity: a systematic review. Am J Obstet Gynecol. 2011;205(3):262.

4. Lumbiganon P, Laopaiboon M, Gulmezoglu AM, Souza JP, Taneepanichskul S, Ruyan P, et al. Method of delivery and pregnancy outcomes in Asia: the WHO global survey on maternal and perinatal health 2007-08. Lancet. 2010;375:490-9.

5. Nikhil A, Desai A, Vijay K, Seema P, Bhumika K, Patel R. Analysis of trends in LSCS rate and indications of LSCS: a study in a medical college hospital GMERS, Sola, Ahmedabad. IJPBS. 2015;2(1):1-5.

6. Caesarean section rates and indications in subSaharan Africa: a multi-country study from medecins sans frontieres; PLoS One. 2012;7(9):e44484.

7. WHO Euro Health for all database, 2014. Available at http://data.euro.who.int/hfadb/(53). Accessed on 15 July 2016.

8. Zaman N. A clinical study on caesarian section in IPGMR (dissertation). Dhaka. Bangladesh College of Physicians and Surgeons; 2015:84-92.

9. Geen JE, Meclean F, Usher SR. Caesarean section study of latin American Hospital. Am J obstet Gynaecol, 1982;142.

10. Indications for and risks of elective caesarean Section. Dtsch Arztebl Int. 2015;112(29-30):489-95.

11. Gillet E, Martens E, Martens G, Cammu HJ. Prelabor caesarean section following IVF/ICSI in olderterm nulliparous women: too precious to push? Pregnancy. 2011;2011:362518.

12. Vaginal birth after cesarean (VBAC): resource overview, 2016. Available at http://www.acog.org/Womens-Health/Vaginal-BirthAfter-Cesarean-VBAC. Accessed on 20 July 2016.

13. Stanton C, Ronsmans C. Recommendations for routine reporting on indications for caesarean delivery in developing countries. Birth. 2008;35:20411.

14. Torloni MR, Betran AP, Souza JP, Widmer M, Allen $\mathrm{T}$, Gulmezoglu M, et al. Classifications for caesarean section: a systematic review. PLoS One. 2011;6:e1456.

Cite this article as: Jawa A, Garg S, Tater A, Sharma U. Indications and rates of lower segment caesarean section at tertiary care hospital - an analytical study. Int J Reprod Contracept Obstet Gynecol 2016;5:3466-9. 